\title{
Peran Badan Pengawas Obat dan Makanan terhadap Peredaran Obat Tradisional yang Mengandung Bahan Kimia Obat Berbahaya dalam Perlindungan Konsumen
}

\author{
Imam Cahyono ${ }^{\bowtie}$, Marsitiningsih, Selamat Widodo \\ Fakultas Hukum, Universitas Muhammadiyah Purwokerto \\ E-mail: imamcahyono03@gmail.com
}

\begin{abstract}
The role of the Food and Drug Supervisory Agency (BPOM) in carrying out its duties, functions and authority is solely to protect the rights of every consumer. The supervision carried out by BPOM is Pre-Market (preliminary supervision carried out before a product is circulated in the community) and Post Market supervision (supervision carried out after the product is circulated in the community). The supervision that has been carried out is still not running optimally and it is not possible to know the distribution of traditional medicinal products containing medicinal chemicals. The purpose of this study was to determine the role of the Food and Drug Administration in dealing with the distribution of traditional medicines containing chemicals. This research is a normative juridical research by obtaining data from books, journals, research results and related laws and regulations. The results of the study show various statutory regulations, government regulations and regional regulations. In order to supervise the distribution of traditional medicines containing medicinal chemicals, the food and drug supervisory agency should be tightened and carry out routine checks in every district or city. Keywords: Food and Drug Supervisory Agency (BPOM), Traditional Medicine, Medicinal Chemistry
\end{abstract}

\begin{abstract}
Abstrak
Peran Badan Pengawas Obat dan Makanan (BPOM) dalam melakukan tugas, fungsi dan kewenangannya semata-semata untuk melindungi hak-hak setiap konsumen. Pengawasan yang dilakukan BPOM yaitu Pre Market (pengawasan pendahuluan yang dilakukan sebelum suatu produk beredar di masyarakat) dan pengawasan Post Market (pengawasan yang dilakukan setelah produk beredar di masyarakat). Dalam pengawasan-pengawasan yang dilakukan masih belum berjalan secara maksimal dan belum dapat mengetahui sampai mana peredaran produk obat tradisional yang mengandung bahan kimia obat beredar. Tujuan dari penelitian ini untuk mengetahui bagaimana peran Badan Pengawas Obat dan Makanan dalam menghadapi perederan obat tradisional yang mengandung bahan kimia. Penelitian ini merupakan penelitian yuridis normative dengan memperoleh data dari buku-buku, jurnal, hasil penelitian dan peraturan perundang-undangan yang terkait. Hasil penelitian menunjukan berbagai peraturan Perundang-undangan, Peraturan Pemerintah dan Peraturan Daerah. Seyogyanya badan pengawas obat dan makanan dalam memberikan pengawasan terhadap peredaran obat tradisional yang mengandung bahan kimia obat harus diperketat dan melakukan pengecekan rutin disetiap daerah kabupaten atau kota.
\end{abstract}

Kata kunci: Badan pengawas obat dan makanan (BPOM), Obat Tradisional, Kimia Obat

Copyright@2019KosmikHukum. All rights reserved.

\section{Pendahuluan}

Dalam perkembangan kelangsungan hidup manusia, setiap orang yang menginginkan hidup sehat akan melakukan berbagai upaya atau cara untuk memulihkan keadaannya secara cepat dan optimal dengan menggunakan berbagai macam obat. Bahkan mereka yang ingin tampil sempurna rela mengorbankan uangnya untuk mendapatkan kesempurnaan itu dengan mengkonsumsi berbagai macam obat. ${ }^{1}$

G. Eka Putra Pratama Arnawa dkk, 2018. Pengawasan Terhadap Perusahaan Yang Mengedarkan Obat - Obatan Impor Tanpa Izin Edar, Jurnal Fakultas Hukum Universitas Udayana, Denpasar, hlm:2. 
Di Indonesia, jamu atau obat tradisional mempunyai kedudukan yang khusus karena merupakan warisan budaya di bidang kesehatan. Pasal 1 angka 1 Peraturan Menteri Kesehatan Republik Indonesia Nomor 07 Tahun 2012 menyebutkan, Obat Tradisional adalah bahan atau ramuan bahan yang berupa bahan tumbuhan, bahan hewan, bahan mineral, sediaan galenik atau campuran dan bahan-bahan tersebut, yang secara turun temurun telah digunakan untuk pengobatan, dan dapat diterapkan sesuai dengan norma yang berlaku dimasyarakat. Hal ini berarti, mutu dan keamanan obat tradisional harus dilakukan sejak awal proses pembuatan obat tradisional, mulai dari pemilihan dan penggunaan, seluruh proses produksi sampai produk- produk yang beredar dimasyarakat mempunyai kualitas yang baik, agar setiap warga negara dapat hidup layak dan untuk menjamin kesejahteraan. ${ }^{2}$

Sesuai dengan Pasal 4 Undang-undang Nomor 8 Tahun 1999 tentang Perlindungan Konsumen menyebutkan Hak konsumen ialah mendapatkan kenyamanan, keamanan dan keselamatan dalam mengkonsumsi barang dan atau jasa serta mendapatkan hak atas informasi yang jelas, benar dan jujur mengenai kondisi dan jaminan barang dan atau jasa yang tersedia. Namun pada kenyataannya obat tradisional jamu yang beredar dipasaran mengandung bahan kimia berbahaya yang mana berdampak negatif bagi kesehatan konsumen.

Pasal 68 Keputusan Presiden Nomor 13 Tahun 2001 tentang Badan Pengawas Obat dan Makanan memiliki fungsi yaitu sebagai pemberi izin dan pengawasan peredaran obat serta pengawasan industri farmasi. Namun realitanya obat tradisional jamu yang mengandung bahan kimia berbahaya beredar di masyarakat, Contoh kasusnya 2 (dua) tempat yang berada ditengah-tengah pemukiman warga Desa Tunjung, kecamatan Jatilawang, kabupaten Banyumas. Menurut Kepala BPOM Semarang, Endang Pudjiwati, Adapun jamu yang diproduksi ada satu jenis di tempat pertama milik PH didusun tunjung kulon dan tujuh jenis di tempat kedua milik BN didusun Tunjung wetan, Rata-rata merupakan jamu kuat dan rematik berbagai merek, di antaranya Akar Lawang, Buah Merah Asam Urat Plus, Enam Sembilan Obat Kuat, Asam Urat Sam Shi. Ada obat untuk rematik serta obat kuat. Jamu itu biasanya dicampur, kalau obat kuat ada sildenafil, tadalafil. Kalau untuk obat rematik itu biasanya parasetamol kemudian juga asam mefenamat, antalgin. Sementara terkait pemasaran produk jamu berbahan kimia obat ini, BPOM Semarang mengaku belum dapat mengetahui sampai mana saja penyebaran produk jamu ilegal tersebut. Pihaknya masih akan mendalami dengan memanggil pemilik pabrik jamu ilegal ini untuk dimintai keterangan. ${ }^{3}$ Kedua pengusaha jamu ilegal yang akan menjalani serangkaian pemeriksaan bisa dijerat Pasal 197 Undang-undang Nomor 36 Tahun 2009 tentang Kesehatan.

Hal ini pula karena kurangnya kesadaran pelaku usaha untuk memproduksi atau membuat obat tradisional jamu sesuai dengan ketentuan yang telah dipersyaratkan.

Berdasarkan Pasal 6 Peraturan Menteri Kesehatan Republik Indonesia Nomor 07 Tahun 2012 tentang Registrasi Obat Tradisional, Obat tradisional yang dapat diberikan izin edar harus memenuhi kriteria sebagai berikut:

1. Menggunakan bahan yang memenuhi persyaratan keamanan dan mutu.

2. Dibuat dengan menerapkan СРОТВ yaitu singkatan dari Cara Pembuatan Obat Tradisional yang Baik.

3. Memenuhi persyaratan Farmakope Herbal Indonesia atau persyaratan lain yang diakui.

4. Berkhasiat yang dibuktikan secara empiris, turun temurun, dan/atau secara ilmiah, dan

5. Penandaan berisi informasi yang objektif, lengkap, dan tidak menyesatkan.

Berdasarkan uraian di atas, penggunaan obat tradisional yang memiliki izin edar harus memenuhi kriteria tertentu. Obat tradisional dilarang mengandung:

Hendri Wasito. Obat Tradisional Kekayaan Indonesia. Graha Ilmu. Yogyakarta. 2011. Hlm. 14

Aktivitas produksi jamu dijatilawang, warga tak curiga https://satelitpost.com/beritautama/35788 diakses pada : 1 Juli 2020 
1. Etil alkohol lebih dari 1\%, kecuali dalam bentuk sediaan tingtur yang pemakaiannya dengan pengenceran.

2. Bahan kimia obat yang merupakan hasil isolasi atau sintetik berkhasiat obat.

3. Narkotika atau psikotropika dan/atau

4. Bahan lain yang berdasarkan pertimbangan kesehatan dan/atau berdasarkan penelitan membahayakan kesehatan.

Badan Pengawas Obat dan Makanan (BPOM) mengimbau agar masyarakat berhati-hati dalam mengonsumsi jamu yang beredar. Pasalnya, tidak semua jamu yang beredar di masyarakat benar-benar dibuat dari bahan-bahan alami. Berdasarkan uraian di atas peneliti tertarik untuk mengkaji terkait Bagaimana peran Badan Pengawas Obat dan Makanan dalam memberikan pengawasan terhadaap peredaran Obat Tradisional yang mengandung bahan kimia obat dan apa hambatan - hambatan Badan Pengawas Obat dan Makanan dalam memberikan pengawasan terhadaap peredaran Obat Tradisional yang mengandung bahan kimia obat.

\section{Rumusan Masalah}

Berdasarkan uraian pendahuluan di atas, permasalahan yang dikaji dalam artikel ini yakni, Pertama, bagaimana peran Badan Pengawas Obat dan Makanan, terhadap peredaran obat tradisional mengandung bahan kimia obat dalam upaya memberikan perlindungan kepada konsumen; Kedua, apa hambatan-hambatan dalam mengawasi Peredaran Obat Tradisional yang Mengandung Bahan Kimia Obat.

\section{Metodologi Penelitian}

Metode penelitian yang digunakan dalam penelitian ini adalah pendekatan Yuridis Normatif yaitu penelitian hukum yang dilakukan dengan pengumpulan data sekunder. Data sekunder meliputi bahan hukum primer, bahan hukum sekunder dan bahan hukum tersier, Penelitian dilakukan dengan studi kepustakaan untuk mendapatkan data yang berbentuk dokumen dan tulisan melalui penelusuran peraturan perundang-undangan, dokumen, literatur ilmiah, penelitian para ahli. Data yang telah diperoleh selanjutnya dianalisis menggunakan logika deduksi.

\section{Hasil dan Pembahasan}

1. Peran Badan Pengawas Obat dan Makanan dalam Memberikan Pengawasan Terhadap Peredaran Obat Tradisional yang Mengandung Bahan Kimia Obat.

Menurut soerjono soekanto Peran adalah suatu pekerjaan yang dilakukan dengan dinamis sesuai dengan status atau kedudukan yang disandang. Status dan kedudukan ini sesuai dengan keteraturan sosial, bahkan dalam keteraturan tindakan semuanya disesuaikan dengan peran yang berbeda. ${ }^{4}$ Badan Pengawas Obat dan Makanan adalah sebuah lembaga di Indonesia yang bertugas mengawasi peredaran obat-obatan dan makanan di Indonesia. Dalam Pasal 2 Huruf b dan c Undang-undang Nomor 7 Tahun 1963 tentang Farmasi, kimia obat adalah obat yang dibuat dari bahan-bahan yang berasal dari binatang, tumbuh-tumbuhan, mineral dan obat syntetis, sedangkan obat asli Indonesia, adalah obat-obat yang didapat langsung dari bahan-bahan alamiah di Indonesia, terolah secara sederhana atas dasar pengalaman dan dipergunakan dalam pengobatan tradisional. Menurut Pasal 1 ayat (8) Undang-undang Republik Indonesia Nomor 36 Tahun 2009 Tentang Kesehatan yang dimaksud dengan Obat adalah bahan atau paduan bahan, termasuk produk biologi yang digunakan untuk mempengaruhi atau menyelidiki sistem fisiologi atau keadaan patologi dalam rangka

Soerjono soekanto, 2009, sosiologi suatu pengantar. (Jakarta : Rajawalipers) hlm. 213 
penetapan diagnosis, pencegahan, penyembuhan, pemulihan, peningkatan kesehatan dan kontrasepsi, untuk manusia. ${ }^{5}$

Menurut Pasal 1 angka 1 Undang-undang Nomor 8 Tahun 1999 tentang Perlindungan Konsumen memberikan pengertian tentang perlindungan konsumen yaitu segala upaya untuk menjamin adanya kepastian hukum untuk memberikan perlindungan kepada konsumen.

Menurut AZ. Nasution, mengartikan bahwa perlindungan konsumen sebagai keseluruhan asas-asas dan kaidah-kaidah yang mengatur dan melindungi konsumen dalam hubugan dan masalahnya dengan para penyedia barang dan/atau jasa konsumen. Nasution menambahkan hukum perlindungan konsumen merupakan bagian dari hukum konsumen yang memuat asas-asas atau kaidah-kaidah bersifat mengatur, dan juga mengandung sifat yang melindungi konsumen. ${ }^{6}$ Konsumen adalah setiap orang pemakai barang dan/atau jasa yang tersedia dalam masyarakat, baik bagi kepentingan diri sendiri, keluarga, orang lain maupun makhluk hidup lain dan tidak untuk diperdagangkan.

Menurut Sidabalok, Perlindungan Konsumen adalah keseluruhan peraturan dan hukum yang mengatur hak dan kewajiban konsumen dan produsen yang timbul dalam usahanya untuk memenuhi kebutuhannya dan mengatur upaya untuk menjamin terwujudnya perlindungan hukum terhadap kepentingan konsumen.

Menurut Shidarta, Perlindungan Konsumen adalah suatu keseluruhan asas-asas dan kaidah-kaidah hukum yang dapat mengatur hubungan dan salah satu masalah antara berbagai pihak satu sama lain yang saling berkaitan dengan barang atau jasa konsumen didalam suatu pergaulan hidup. ${ }^{7}$

Perlindungan konsumen adalah istilah yang dipakai untuk menggambarkan perlindungan hukum yang diberikan kepada konsumen dalam usahanya untuk memenuhi kebutuhannya dari hal-hal yang merugikan konsumen itu sendiri. Perlindungan konsumen mempunyai cakupan yang luas, meliputi perlindungan konsumen terhadap barang dan jasa, yang berawal dari tahap kegiatan untuk mendapatkan barang dan jasa hingga sampai akibatakibat dari pemakaian barang dan/atau jasa tersebut. ${ }^{8}$ Dalam penelitian ini konsumen yang dimaksud adalah konsumen yang memakai, menggunakan dan mengkonsumsi obat tradisional yang mengandung bahan kimia obat berbahaya, tidak sesuai dosis dan takaran yang dibuat oleh pelaku-pelaku usaha curang atau tidak bertanggung jawab demi mendapatkan keuntungan lebih.

Asas Perlindungan Konsumen Berdasarkan Undang-Undang Perlindungan Konsumen Pasal 2, menyebutkan bahwa asas perlindungan konsumen ada 5 asas, yaitu:

1. Asas Manfaat.

2. Asas Keadilan.

3. Asas Keseimbangan.

4. Asas Keamanan dan Keselamatan Konsumen.

5. Asas Kepastian Hukum. ${ }^{9}$

Pakar masalah konsumen di Belanda, Hondius menyimpulkan, para ahli hukum pada umumnya sepakat mengartikan konsumen sebagai, pemakai produksi terakhir dari benda dan jasa. ${ }^{10}$ Hak-hak Konsumen berdasarkan Pasal 4 Undang-Undang Nomor 8 Tahun 1999 Tentang Perlindungan Konsumen, meliputi:

\footnotetext{
5 Hadi Mulyansyah, Peranan Balai Besar Pengawas Obat Dan Makanan Dalam Memberantas Tindak Pidana Peredaran Obat Keras Di Sarana Yang Tidak Memiliki Keahlian Dan Kewenangan Berdasarkan Undang-Undang Nomor 36 Tahun 2009 Tentang Kesehatan Di Provinsi Riau. JOM Fakultas Hukum Volume III Nomor 2, Oktober 2016.

Ahmad Zuhairi, 2016, Hukum Perlindungan Konsumen \& Problematikanya, Jakarta: GH Publishing, hlm. 17 Pengertian konsumen https://dosenpintar.com diakses pada : 2 Juli 2020

Zulham, 2013, Hukum Perlindungan Konsumen, Jakarta: Kencana, hlm, 21-22.

Happy Susanto,2008, Hak-Hak Konsumen Jika Dirugikan, Jakarta: Transmedia Pustaka, hlm. 17-18

10 Susanti Adi Nugroho, Proses Penyelesaian Sengketa Konsumen Ditinjau dari Hukum Acara Serta Kendala dan Implementasinya, (Jakarta: Prenadamedia, 2015), cet.3, hlm.60.
} 
Kosmik Hukum Vol. 19 No. 2 (2019): 110-117

E-ISSN: 2655-9242 | P-ISSN: 1411-9781

DOI: 10.30595/kosmikhukum.v19i2.8216

a. Hak atas kenyamanan, keamanan, dan keselamatan dalam mengonsumsi barang dan/atau jasa.

b. Hak untuk memilih dan mendapatkan barang dan/atau jasa sesuai dengan nilai tukar dan kondisi serta jaminan yang dijanjikan.

c. Hak atas informasi yang benar, jelas, dan jujur mengenai kondisi dan jaminan barang dan/atau jasa. Hak untuk didengar pendapat dan keluhannya atas barang dan/atau jasa yang digunakan.

d. Hak untuk mendapatkan advokasi, perlindungan dan upaya penyelesaian sengketa perlindungan konsumen secara patut.

e. Hak untuk mendapatkan pembinaan dan pendidikan konsumen. Hak untuk diperlukan atau dilayani secara benar dan jujur serta tidak diskriminatif.

f. Hak untuk mendapatkan kompensasi, ganti rugi dan/atau penggantian apabila barang dan/atau jasa yang diterima tidak sesuai dengan perjanjian atau tidak sebagaimana mestinya.

g. Hak-hak yang diatur dalam peraturan perundang-undangan lainnya ${ }^{11}$.

Berdasarkan Pasal 4 Peraturan Presiden Nomor 80 Tahun 2017 tentang Badan Pengawas Obat dan Makanan dalam melaksanakan tugas Pengawasan Obat dan Makanan, BPOM mempunyai kewenangan:

a. Menerbitkan izin edar produk dan sertifikat sesuai dengan standar dan persyaratan keamanan, khasiat/manfaat dan mutu, serta pengujian obat dan makanan sesuai dengan ketentuan peraturan perundang-undangan.

b. Melakukan intelijen dan penyidikan di bidang pengawasan Obat dan Makanan sesuai dengan ketentuan peraturan perundang - undangan.

c. Pemberian sanksi administratif sesuai dengan ketentuan peraturan perundangundangan.

Sesuai dengan amanat yang tercantum dalam Peraturan Presiden, BPOM menyelenggarakan fungsi:

a. Penyusunan kebijakan nasional di bidang pengawasan Obat dan Makanan.

b. Pelaksanaan kebijakan nasional di bidang pengawasan Obat dan Makanan.

c. Penyusunan dan penetapan norma, standar, prosedur, dan kriteria di bidang Pengawasan Sebelum Beredar dan Pengawasan Selama Beredar.

d. Pelaksanaan Pengawasan Sebelum Beredar dan Pengawasan Selama Beredar.

e. Koordinasi pelaksanaan pengawasan Obat dan Makanan dengan instansi pemerintah pusat dan daerah.

f. Pemberian bimbingan teknis dan supervisi di bidang pengawasan Obat dan Makanan.

g. Pelaksanaan penindakan terhadap pelanggaran ketentuan peraturan perundangundangan di bidang pengawasan Obat dan Makanan.

h. Koordinasi pelaksanaan tugas, pembinaan, dan pemberian dukungan administrasi kepada seluruh unsur organisasi di lingkungan BPOM.

i. Pengelolaan barang milik/kekayaan negara yang menjadi tanggung jawab BPOM. ${ }^{12}$

Dalam menjalankan tugas dan fungsinya sebagai pengawas obat dan makanan dalam wilayah regional, BPOM memiliki beberapa program kegiatan pengawasan yakni:

1. Pre-market merupakan pengawasan pendahuluan yang dilakukan sebelum suatu produk beredar di masyarakat. Tahapan yang dilakukan antara lain; sertifikasi, registrasi dan distribusi produk. Pre market diantaranya dilakukan saat pelaku usaha/importer mengurus pendaftaran di BPOM dan saat pemeriksaan kelengkapan dan keabsahan dokumen dan barang di pintu gerbang pelabuhan atu bandara yang dilakukan oleh petugas Bea dan Cukai.

11 Haerandi, marilang, 2020. Perlindungan Konsumen Terhadap Obat Tradisional Ilegal. Jurnal Universitas Islam Negri Makasar. Vol 2 Nomor 1. Hlm. 9

12 Peran BPOM Berdasarkan Peraturan Perundang-undangan", Diakese pada: https://jdih.pom.go.id Diakses pada: 1 juli 2020 
2. Post-market merupakan pengawasan yang dilakukan sestelah suatu produk beredar di masyarakat. Pengawasan ini dilakukan dengan melakukan inspeksi ke pasar, supermarket maupun toko retail lainnya untuk mengambil sampel obat tradisional yang dicurigai berbahaya bagi masyarakat dan kemudian diuji laboratorium. ${ }^{13}$

Dalam sistem ini, BPOM membagi kegiatan pengawasan dalam tujuh (7) kategori, antara lain sebagai berikut:

1. Regulasi adalah Pengawasan yang dilakukan BPOM dilakukan berdasarkan peraturan perundang-undangan yang berlaku. Dalam melakukan pengawasan Obat BPOM mengacu kepada UU Kesehatan.

2. Standarisasi adalah mengenai takaran zat-zat yang digunakan dalam pembuatan makanan maupun ukuran spesifik bentuk daripada obat tradisional tersebut.

3. Registrasi adalah tahapan dimana produk-produk yang telah selesai produksi akan diberikan nomor untuk menyatakan bahwa produk tersebut telah memenuhi standar pembuatan.

4. Inspeksasi adalah penyuluhan yang dilakukan ke pasar, swalayan atau retail - retail lainnya secara berkala guna memeriksa obat tradisional yang dicurigai berbahaya bagi kesehatan.

5. Sampling adalah kegiatan pengambilan contoh obat tradisional yang dicurigai berbahaya yang kemudian akan diujikan ke laboratorium.

6. Public warning adalah pernyataan resmi yang dikeluarkan oleh BPOM apabila ditemukan obat tradisional yang dapat membahayakan kesehatan maupun keselamatan konsumen.

7. Layanan konsumen dibuat dengan tujuan untuk menerima aduan oleh konsumen agar nantinya konsumen dapat merasa aman dan nyaman dalam mengkonsumsi produk-produk obat tradisional.

2. Hambatan - hambatan Badan Pengawas Obat dan Makanan dalam Memberikan Pengawasan terhadap Peredaran Obat Tradisional yang Mengandung Bahan Kimia Obat.

Hambatan-hambatan yang dihadapi Badan POM dalam pengawasan terhadap peredaran obat tradisional yang mengandung bahan kimia ada 2 (dua) yaitu hambatan internal dan hambatan eksternal.

Adapun Hambatan Internal meliputi:

1. Keterbatasan staf Badan Pengawas Obat dan Makanan baik yang berada di pusat maupun di provinsi sehingga menjadikan kinerja Badan Pengawas Obat dan Makanan tidak maksimal. Jumlah staf yang terbatas ini tentu mempengaruhi pelaksanaan tugas pengawasan dari Badan Pengawas Obat dan Makanan, apalagi ditambah dengan wilayah kerja yang sangat luas, sehingga akan berpengaruh pada intensitas pengawasan yang rendah ataupun lingkup pengawasan produk yang lebih sempit.

2. Pengawasan Badan Pengawas Obat dan Makanan yang dilakukan secara berkala dan acak, sehingga sering disalah gunakan oleh pengusaha untuk mengambil kesempatan dalam kesempitan untuk memasukkan produk ke Indonesia pada periode saat tidak dilakukan pengawasan.

Sedangkan Hambatan Eksternal meliputi:

1. Kurang ketatnya sistem pengawasan

2. Kurang dipatuhinya persyaratan-per-syaratan peredaran obat tradisional yang mengandung bahan kimia karena tidak jelasnya informasi yang tertera pada label yang dicantumkan pada produk obat tradisional tersebut.

13 Nurhayati, 2009, "Efektivitas Pengawasan Badan Obat dan Makanan", Jurnal Hukum, Fakultas Hukum Universitas Gajah Mada, h. 213. 
Kosmik Hukum Vol. 19 No. 2 (2019): 110-117

E-ISSN: 2655-9242 | P-ISSN: 1411-9781

DOI: $10.30595 /$ kosmikhukum.v19i2.8216

3. Masih rendahnya kesadaran hukum konsumen untuk melakukan pengaduan atau laporan kepada pemerintah ataupun lembaga perlindungan konsumen. ${ }^{14}$

\section{Penutup}

\section{Kesimpulan}

Peran BPOM dalam melakukan tugas, fungsi dan kewenangannya semata-semata untuk melindungi hak-hak setiap konsumen. Pengawasan yang dilakukan BPOM yaitu pengawasan Pre-Market (pengawasan pendahuluan yang dilakukan sebelum suatu produk beredar di masyarakat) dan pengawasan Post-Market (pengawasan yang dilakukan setelah produk beredar di masyarakat). Dalam pengawasan-pengawasan yang dilakukan masih belum berjalan secara maksimal karena, kurangnya tenaga kerja dan pengecekan obat tradisional disetiap daerah masih dilakukan secara berkala jadi pelaku usaha mudah dalam melakukan peredaran obat tradisional mengandung bahan kimia berbahaya

\section{Saran}

Pertama, Penambahan jumlah pegawai, agar memadai dalam melakukan tugas BPOM secara maksimal. Kedua, Memberikan peringatan berupa penyitaan, denda yang besar serta tindakan tegas terhadap pelaku usaha yang curang dan tidak bertanggung jawab.

\section{Daftar Pustaka}

Ahmad Zuhairi, 2016, Hukum Perlindungan Konsumen \& Problematikanya, Jakarta: GH Publishing.

Bahan Kimia Obat Dalam Obat Tradisional dan Efek Samping, https://pharmacy.uii.ac.id diakses pada: 2 Juli 2020. Pukul 23.00 WIB

G. Eka Putra Pratama Arnawa dkk, 2018 "Pengawasan Terhadap Perusahaan Yang Mengedarkan Obat-Obatan Impor Tanpa Izin Edar", Jurnal Fakultas Hukum Universitas Udayana, Denpasar.

Gede Jaya Kesuma dkk, 2018, “Peranan Balai Besar Pengawas Obat Dan Makanan Provinsi Bali dalam memberikan perlindungan terhadap konsumen dengan peredaran obat yang mengandung zat berbahaya (Policresulen)" , Jurnal Fakultas Hukum Universitas Udayana, Denpasar.

Hadi Mulyansyah, "Peranan Balai Besar Pengawas Obat Dan Makanan Dalam Memberantas Tindak Pidana Peredaran Obat Keras Di Sarana Yang Tidak Memiliki Keahlian Dan Kewenangan Berdasarkan Undang-Undang Nomor 36 Tahun 2009 Tentang Kesehatan Di Provinsi Riau". JOM Fakultas Hukum Volume III Nomor 2, Oktober 2016.

Haerandi, marilang, 2020. Perlindungan Konsumen Terhadap Obat Tradisional Ilegal. Jurnal Universitas IslamNegri Makasar. Volume 2 Nomor 1.

Happy Susanto,2008, Hak-Hak Konsumen Jika Dirugikan, Jakarta: Transmedia Pustaka.

Hendri Wasito. Obat Tradisional Kekayaan Indonesia. Graha Ilmu. Yogyakarta. 2011.

Ivan Fauzani Raharja, Penegakan Hukum Sanksi Administrasi Terhadap Pelanggaran Perizinan, Jambi, 2013

14 Syafrina Maisusri, 2016 "Penegakan Hukum Terhadap Tindak Pidana Peredaran Obat Impor Yang Tidak Memiliki iIzin Edar Oleh Penyidik Pegawai Negri Sipil Balai Besar Pengawas Obat dan Makanan Di Pekanbaru", Vol III Nomor 2, JOM Fakultas Hukum, hlm,10 
Kelik Pramudya, Sanksi Administrasi dan Pidana Dalam UUPK https://click-gtg.blogspot.com Diakses pada: 1 Juli 2020. Pukul 19.00 WIB

M Afif Dalma, Pengertian Konsumen https://dosenpintar.com diakses pada: 2 Juli 2020. Pukul 22.00 WIB

Muhammad Alfan Nur Suhaid Bambang Eko Turisno R Suharto, 2016, "Perlindungan konsumen Terhadap Peredaran obat Tanpa Izin Edar yang Dijual Secara Online di Indonesia" Vol 5 Nomor 3, Jurnal Fakultas Hukum Universitas Diponegoro, semarang.

Ni Komang Ayu Nira Relies Rianti, 2017, “Tanggung Jawab Pelaku Usaha Terhadap Konsumen Dalam Hal Terjadinya Shortweighting Ditinjau Dari Undang-Undang Nomor 8 Tahun 1999 Tentang Perlindungan Konsumen." Vol. 6, No. 4, Jurnal Magister Hukum, Fakultas Hukum, Universitas Udayana, Bali.

Nurhayati, 2009, "Efektivitas Pengawasan Badan Obat dan Makanan", Jurnal Hukum, Fakultas Hukum Universitas Gajah Mada

Peran BPOM Berdasarkan Peraturan Perundang-undangan", Dimuat pada: https://jdih.pom.go.id Diakses pada: 1 juli 2020. Pukul 14.00 WIB

Peraturan Menteri Kesehatan Republik Indonesia Nomor 007 Tahun 2012 tentang Registrasi Obat Tradisional

Peraturan Presiden Nomor 80 Tahun 2017 Tentang Badan Pengawas Obat dan makanan Dalam Melaksanakan Tugas Pengawasan Obat dan Makanan

Soerjono soekanto, 2009, sosiologi suatu pengantar. Jakarta: Rajawalipers

Susanti Adi Nugroho, Proses Penyelesaian Sengketa Konsumen Ditinjau dari Hukum Acara Serta

Syafrina Maisusri, 2016 “Penegakan Hukum Terhadap Tindak Pidana Peredaran Obat Impor Yang Tidak Memiliki iIzin Edar Oleh Penyidik Pegawai Negri Sipil Balai Besar Pengawas Obat dan Makanan Di Pekanbaru", Vol III Nomor 2, JOM Fakultas Hukum.

Tri Jata Ayu Pramesti, Arti Pidana Pokok dan Pidana Tambahan https://m.hukumonline.com diakses pada: 1 Juli 2020. Pukul 22.00 WIB

Triono Yulianto, Aktivitas Produksi Jamu di Jatilawang, Warga Tak Curiga https:// satelitpost.com/beritautama/35788 diakses pada: 1 Juli 2020. Pukul 17.00 WIB

Undang-Undang Nomor 36 Tahun 2009 tentang Kesehatan.

Undang-undang Nomor 7 tahun 1963 tentang Farmasi

Undang-Undang Nomor 8 Tahun 1999 tentang Perlindungan Konsumen

Zulham, 2013, Hukum Perlindungan Konsumen, Jakarta: Kencana. 